\title{
Science Education and the Commonplaces of Science
}

By: Jenifer V. Helms, Heidi B. Carlone

This is the accepted version of the following article:

Helms, J. V. and Carlone, H. B. (1999), Science education and the commonplaces of science. Science Education, 83(2), 233-245. doi: 10.1002/(SICI)1098-237X(199903)83:2<233::AIDSCE8>3.0.CO;2-9,

which has been published in final form at http://dx.doi.org/10.1002/(SICI)1098237X(199903)83:2<233::AID-SCE8>3.0.CO;2-9.

***(C) Wiley. Reprinted with permission. No further reproduction is authorized without written permission from Wiley. This version of the document is not the version of record. Figures and/or pictures may be missing from this format of the document. $* * *$

\begin{abstract}
:
In this paper, we describe science as a set of "commonplaces," similar to Schwab's commonplaces of teaching, for framing the nature of science and science education (Schwab, J. J. [1978]. Science Curriculum, and Liberal Education. Chicago: University of Chicago Press). Framed thoughtfully, these commonplaces have the potential to incorporate insights from a variety of perspectives. We propose four formulations of the commonplaces of science, based on distinct views of the nature of science, and explore the consequences of each. We argue that, although there are strengths to each formulation, some commonplaces prove more comprehensive than others in capturing the essence of science for the purposes of developing curriculum, educating science teachers, and conducting science education research.

Keywords: Education | Curriculum | Science Education | Heuristic

\section{Article:}

\section{INTRODUCTION}

The nature of science as a human enterprise is contested among science educators. Descriptions and definitions of science emanating from science textbooks and science education reform efforts reflect different viewpoints (AAAS, 1989, 1993; NRC, 1996; California Department of Education, 1990). Science education researchers have also extended the conversation, debating such issues as the multicultural nature of science (Atwater, 1994; Good, 1995; Krugly-Smolska, 1996; Loving, 1995; Southerland, 1996; Stanley \& Brickhouse, 1994), the role of belief in scientific inquiry (Cobern, 1995), and the degree to which science-related social issues belong in the science classroom (Cunningham, 1995; Solomon \& Aikenhead, 1994; Yager, 1996). Scholars in science studies provide yet additional views, drawing from disciplines like psychology,
\end{abstract}


sociology, an- thropology, and gender studies (Giere, 1988; Harding, 1986, 1990; Keller, 1985; Latour \& Woolgar, 1986; Longino, 1990; Restivo, 1994; Shapin, 1984; Traweek, 1988).

Recently, science education reform documents have called for teachers to obtain a deeper understanding of the nature of science-for example, about the context of science, the history or philosophy of science, or the ways in which science interacts with technology and society (AAAS, 1989, 1993; Duschl, 1990; Matthews, 1991, 1994; NRC, 1996). At the same time, science education researchers have attempted to characterize teachers' science knowledge and to identify what is necessary to teach effectively about the nature of science (Brickhouse, 1990; Duschl \& Wright, 1989; Gallagher, 1991; Lederman, 1992; Zeidler \& Lederman, 1987). Many of these studies provide insight into how teachers understand the nature of science and whether or not their understandings are consistent with contemporary views. Some of them address whether or not understandings are reflected in practice. This research, it is hoped, will inform policy with respect to curriculum, teacher education, and professional development.

Given the variety of ways science can be described, that is, in cultural, psychological, sociological, and philosophical terms, how should researchers, teachers, and teacher educators proceed? What aspects of science should be highlighted in a study of and about science and science education? In this article we think of science as a set of “commonplaces,” similar to J. J. Schwab’s (1978) commonplaces of teaching, for framing the nature of science and science education. Framed thoughtfully, these commonplaces have the potential to incorporate insights from a variety of perspectives.

In the following sections, we propose four formulations of the commonplaces of science based on distinct views of the nature of science, and explore the consequences of each. We argue that, although there are strengths to each formulation, some commonplaces prove more comprehensive than others in capturing the essence of science for the purposes of developing curriculum, educating science teachers, and conducting science education research.

\section{THE “COMMONPLACES” HEURISTIC}

A heuristic can be described as a flexible device employed to organize information for making sense of a situation or problem. Jerome Bruner (1960) contrasts the use of a heuristic with an algorithm:

A heuristic procedure . . . is in essence a non-rigorous method of achieving solutions of problems. ... An algorithm, on the other hand, is a procedure for solving a problem which, if followed accurately, guarantees that in a finite number of steps you will find a solution to the problem if the problem has a solution. (p. 63)

The aim of this work is to provide a heuristic device that is flexible, yet powerful enough to identify central aspects of science for the analysis and improvement of research and practice in 
science education. A robust heuristic for the analysis of science education, we argue, attends to the many facets of scientific practice.

Schwab’s (1978) “commonplaces” heuristic for education provides a starting place for the development of a more dynamic heuristic for science. He described the educational experience as consisting of: someone (a teacher) teaching something (subject matter) to someone (a learner) in some place and moment in time (milieu). In reference to these four commonplaces, Schwab explained the importance of each, and how each must occupy equal positions in the overall picture:

Defensible educational thought must take account of four commonplaces of equal rank: the learner, the teacher, the milieu, and the subject matter. None of these can be omitted without omitting a vital factor in educational thought and practice. No one of them may be allowed to dominate the deliberation unless that domination is conscious and capable of defense in terms of the circumstances. (p. 371)

Schwab called for the "coordination, not superordination-subordination" of the commonplaces of education. He suggested that "[f]our factors, no one sufficient in itself, no one indispensable, are concerned in maintaining coordination” (p. 374).

Similarly, to construct and use a more holistic description of the practice of science, its various dimensions must be considered in coordination with one another. Hence, one of the primary strengths in using a commonplaces heuristic for science is that it takes into consideration various aspects of the nature of science and also shows how the various aspects are related. This coordination is significant, as many studies by science educators addressing the nature of science employ a relatively narrow operational definition of science by limiting their descriptions and analyses to one or two aspects of internal (micro) processes of science (e.g., how scientific knowledge is constructed) or, even more rare, external (macro)processes of science (e.g., the interaction between science and society) (Cunningham, 1995; see Lederman, 1992, for a review of the nature-of-science studies in science education). Indeed, Meichtry (1993) explained that many studies use the terms "nature of science" and "nature of scientific knowledge" synonomously when, in fact, the nature of science also involves the nature of the scientific enterprise, the nature of scientists, and the nature of the sociocultural context. The commonplaces framework allows us to consider all of these aspects of the nature of science together.

This leads to a second strength of the commonplaces framework: it keeps all aspects in the foreground and on an even plane-there is no hierarchy structuring the various dimensions. Equal attention is given to multiple facets of science. Therefore, this heuristic demands that each of the commonplaces are necessary for the definition of science; it is the sum of the commonplaces that captures the nature of science and enables us to determine what (if anything) is unique about it. 
Finally, multiple interpretations may exist for each of the commonplaces we propose. This feature, as we hope to demonstrate in the following pages, is considered a strength: for a framework to be useful it needs to be meaningful across a range of situations.

In summary, why is thinking about science as a set of commonplaces useful or important? We suggest three reasons. First, it illustrates the interrelatedness of the various dimensions of the scientific endeavor, thereby making it difficult to define science merely as "method" or "a body of knowledge." Second, it provides a means for highlighting multiple dimensions of science at once, rather than focusing solely on one or two dimensions, as is common practice for research in science education. Third, the commonplaces heuristic allows for multiple interpretations and use in a wide range of situations, thus increasing its utility and power.

\section{THE COMMONPLACES OF SCIENCE}

How, then, might we formulate the commonplaces of science? At issue, here, are the central aspects of science that we wish to capture to improve the study and practice of science education. Our argument is based on the premise that the most robust descriptions of science include both micro and macro descriptions of its practice.

\section{Formulation \#1}

Consider the first formulation of the commonplaces of science, hereafter referred to as \#1:

Science is an activity in which evidence is gathered through observation and experiment to explain and predict natural phenomena.

Drawing on empiricist philosophy, this formulation highlights the importance of evidence, observation, and experiment in achieving two of the major goals of science, namely, explanation and prediction of natural phenomena. This formulation, capturing the empirical spirit of science, embodies traditional notions of what science is and how science is done (Chalmers, 1982). In the introductory chapter to his book What is this Thing Called Science, Chalmers (1982) explained that most people view science in this way: "scientific theories are derived in some rigorous way from the facts of experience acquired by observation and experiment” (p. 1). While he goes on to refute this characterization of science through an analysis of the theory-dependence of observation, it remains a potent and widely held view. While some brands of pure empiricism have fallen out of favor in philosophy of science circles, it has gained a great deal of purchase in the arena of science education reform, as will be explained shortly.

How might one utilize \#1 for a critical examination of a science learning context? First, one could examine how each commonplace is being interactionally defined in the setting. For example, does “evidence” imply students are utilizing memorized facts from a textbook, or are 
they using results garnered from observation and experiment, or both? On what basis are students constructing explanations and offering predictions? Is there an effort to make explicit the connection between evidence and explanation (Millar, 1997)? In what ways are observation and experiment utilized in the setting? Does "experiment" imply following a set of cookbook procedures to come up with an expected answer, or does it involve investigating studentgenerated questions and socially negotiating the meaning of the observations?

Furthermore, one could examine if one commonplace eclipses others in terms of devoted instructional time. In other words, might students be spending more time explaining results of experiments and less time applying what they learned through creating predictions about similar phenomena? Recall that the commonplaces heuristic implies that equal attention be given to each commonplace, without one commonplace receiving more emphasis than the others. As such, this formulation implies equal attention be given to evidence, observation, experiment, explanation, prediction, and natural phenomena.

Although, as mentioned earlier, it is generally agreed that an empirical model of science is not an accurate portrayal of the nature of science (Duschl, 1994), this model continues to pervade much of the popular view of the nature of science. It could be argued that this formulation, applied to a critical examination of a science learning context, exemplifies elements of many current visions of effective science instruction. A science learning context that stands up to \#1 would, indeed, include many elements of instruction called for by the leading reform documents (AAAS, 1993; NRC, 1996). Undeniable in these documents is a strong emphasis on inquiry-oriented instruction. Consider, for example, the National Science Education Standard's (1996) definition of scientific inquiry:

Scientific inquiry refers to the diverse ways in which scientists study the natural world and propose explanations based on the evidence derived from their work. . . . Inquiry is a multifaceted activity that involves making observations; posing questions; examining books and other sources of information to see what is already known; planning investigations; reviewing what is already known in light of experimental evidence; using tools to gather, analyze, and interpret data; proposing answers, explanations, and predictions; and communicating the results. ... Students will engage in selected aspects of inquiry as they learn the scientific way of knowing the natural world, but they also should develop the capacity to conduct complete inquiries. (p. 23; our emphasis)

So, while the empiricist philosophy of science no longer represents what many theorists consider a complete picture of how science is done, it remains a central aspect of reformbased instruction. As historians, philosophers, and sociologists of science have shown, however, the empiricist philosophy maintains an observational-theoretical distinction. That is, the notion that scientific knowledge develops inductively in a logical process moving from empirical fact to the development of scientific theory and knowledge is not supported by over three decades of scholarship from historians, philosophers, and sociologists of science (Chalmers, 1982; Duschl, 
1994; Kuhn, 1962). Thus, one of the flaws of \#1 is that it may not take into consideration that what counts as evidence, what is observed, what explanations are constructed or what predictions ensue are dependent upon theoretical commitments. Incidentally, this may also be a flaw of the definition of “evidence” in the National Science Education Standards (1996):

Evidence consists of observations and data on which to base scientific explanations. Using evidence to understand interactions allows individuals to predict changes in natural and designed systems. (p. 117)

Thus, while the commonplaces in \#1 are representative of the central aspects of reformbased instruction, the heuristic might be strengthened by utilizing more recent scholarship from historians, philosophers, and sociologists of science. What might a commonplaces heuristic that takes into account some of this recent scholarship look like? We turn to our second formulation of commonplaces for some answers.

\section{Formulation \#2}

Let us consider a second set of commonplaces (\#2):

Science is an activity through which people negotiate the production of artifacts and facts in order that they may explain, predict, and control natural phenomena in their interests and the interests of others.

This formulation emphasizes yet another set of issues. Here, the notion that science is driven by interests challenges the idea of pure science (Restivo, 1994). In part, \#2 is informed by interest theorists, such as Barnes and Shapin (1979). In their book, Natural Order, Barnes and Shapin include a collection of works that utilize sociological and anthropological methods to describe and analyze the processes of science. A recurrent theme throughout the book is the identification of social interests in shaping the production of knowledge, as well as the technical value of the resulting representations of knowledge. Seeking to understand scientific knowledge and ideas by referring to people, activities, and interests, the authors of this book make explicit their focus of natural knowledge as culture. This formulation has a distinctive political overtone that reflects a view of science as not purely a knowledge-building enterprise, but one in which individuals vie for power and control.

While \#2 highlights the notion that science is not value-free and that outside influences are a part of doing science, it also implies a distinct view of the ways in which scientific knowledge is created. In part, this formulation is informed by a branch of sociology of science called laboratory studies, which provide ethnographic accounts of how scientific statements evolve from scientific practice (e.g., Latour and Woolgar, 1986; Knorr-Cetina, 1995; Traweek, 1988). The descriptions of science provided by these scholars reveal that scientific knowledge is the product of social work (Restivo, 1994) and that the laboratory exists as a "fact factory" (KnorrCetina, 1995), whereby facts are created, not discovered by reliance on a rule-bound scientific 
method. Thus, while \#1 rendered the process of creating scientific knowledge neat and unproblematic, \#2 highlights the social and personal influences on knowledge production.

A strength of this formulation is that it highlights aspects of the nature of science often ignored or glossed over in traditional science instruction. Scientific knowledge is usually taught as unambiguous, replicable truths discovered by adherence to a rule-bound scientific method that rests on observations and is confirmed by experiments (Collins \& Shapin, 1989). This tidy notion of science is a myth debunked by scholars studying the sociology of scientific knowledge. Some science educators claim that utilizing scholarship from the sociology of science can make science more accessible and inclusive (e.g., Cunningham \& Helms, 1998; Kelly, Carlsen, \& Cunningham, 1993). That is, having students understand that science is a social process, involving human values, beliefs, and uncertainty, may make the study of science less formidable and alienating. This formulation of commonplaces makes the enterprise of science more human.

In addition, there is a commitment to extend the goals of explanation and prediction in \#1 to include "control” as another goal of science in this second set of commonplaces. In doing so, \#2 highlights what some may say is a less desirable goal of science (Keller, 1985).

While this formulation takes into consideration literature from the sociology of science, its scope is largely bounded to microsociological concepts (Cunningham, 1995). That is, using Cunningham's (1995) framework to describe the work in sociology of science, microsociological aspects of science consider such things as how scientific knowledge is constructed in the laboratory and how sociocultural concerns or beliefs of the participants influence and are influenced by scientific practice. Although \#2 highlights the "interests of others," its scope is largely microsociological. Focusing primarily on the micro or internal processes of science may result in perpetuating the notion that science exists in a sociocultural and historical vacuum, a notion that has been challenged by some sociologists. We now turn to a third formulation, which broadens the scope of science by highlighting its interaction with society.

\section{Formulation \#3}

Science is an activity in which people studying natural phenomena use and produce technologies to pursue questions and solve problems that influence and are influenced by external social structures.

In this formulation, the definition of context is broadened considerably compared with \#1 and \#2. Based on work from scholars who write about the larger context of science, this formulation highlights what Cunningham (1995) calls macrosociological aspects of science, which address the influence of external social, political, cultural, religious, and economic factors on science. Scholars in this area focus on the relationship between and among politics, economics, power, autonomy, and the status and boundaries of science (e.g., Callon, 1995; Cozzens \& Woodhouse, 1995; Cunningham \& Helms, 1998; Dickson, 1988; Gieryn, 1995). 
Like \#2, this formulation highlights aspects of the nature of science that may not be acknowledged or emphasized in traditional science instruction. But, unlike \#2, it makes explicit the connection between external factors and science. The agenda in this formulation is similar to that forwarded by Gieryn (1995), who argues that, because the social, local nature of scientific knowledge has been well established by laboratory studies, it is time for this scholarship to move “out of the lab.” Broadening the interpretive and analytic lens, Gieryn (1995) argues, "moves science (the practices, claims, and instruments in need of mapping) closer to places where matters of power, control, and authority are settled” (p. 440).

An obvious consequence of the formulation is the dissolution of the boundary between science and society, making the connection between the two tight and inevitable. An example of this connection is found in the inclusion of "technology" as a commonplace of science. While the terms "science” and "technology” usually operate as separate conceptual categories, \#3 pushes the boundaries of what is traditionally thought of as science.

For example, in her analysis of the relationship between science and culture, Haraway (1990) suggests that, until we recognize ourselves as cyborgs - part human, part machine-we cannot fully appreciate the connection between science, technology, and ourselves. She claims that as technological objects, we cannot separate ourselves from the science we produce and questions how we can best contend with science when we are science, itself. She presents a political agenda that attempts to dissolve the boundary between nature and culture, human and machine. Indeed, says Haraway, the boundaries have never really existed. Ultimately, Haraway calls for a science that is grounded in nonoppression and love, one that recognizes that we are only objective in our partiality, and that there is no innocence in the production and use of knowledge.

How has science education addressed the relationships among science, society, and technology? The Science-Technology-Society approach to science education utilizes a conception of science similar to \#3. While it has had to "fight hard" to gain legitimacy in science education circles (Solomon \& Aikenhead, 1994, p. 1), it offers contemporary perspectives on science and society that includes social responsibility. Indeed, in contrasting what she terms a "traditional, contemplative science education” with an STS education, Solomon (1994) explains that:

The [traditionalists] see the science classroom as a haven from the untidy unjust world of emotions, and they use the classroom to teach logical truths. But the danger is that the public, including school children, translate that lofty picture of scientific inquiry into a cartoon image where amoral scientists pursue their intellectual goals at the expense of animal and human welfare. The traditionalists argue that moral education is all right in its proper place, in the humanities classroom, but not in science. The STS teachers reply that citizens and future scientists alike need to marry the intellectual study of science to feelings for moral right and social justice. Science and feelings cannot just be stitched together after the uncaring cartoon image has already been planted in the minds of children. (p. 10) 
While the social, cultural, technological underpinnings of science should be a part of a meaningful science education, aspects of the traditional, contemplative approach to science education cannot be ignored. Framing science as situated in larger contexts without reference to internal processes, as we have done in \#3, may unnecessarily restrict our vision of science.

Each of these formulations \#1-3 have strengths as well as limitations. How can we draw on the strengths of each formulation to construct a more robust heuristic? That is, how can we formulate an heuristic that is multifaceted, flexible, and powerful enough to capture the central aspects of science? Let us consider the fourth formulation, which is our attempt to do this.

\section{Formulation \#4}

Science is an activity in which people employ lenses and methods to investigate questions and produce knowledge concerning natural phenomena, all in a particular context, in the service of some goal or set of goals.

Science as Multifaceted. This formulation emerged from what we believe are the central features of the foregoing commonplaces; that is, it captures the empirical as well as sociological features of the scientific endeavor to provide a complex, flexible, and powerful heuristic for the analysis of science and science education. It brings to the fore elements of science that may be glossed over in representations and conceptions of, and rhetoric about, science and science education.

The first three formulations each provide a distinctive view of science based on scholarship in different areas of science studies. Formulation \#1 highlights the empirical nature of science, which captures much of the spirit of leading reform documents. In \#4, this aspect is represented in the "lenses," "methods," and "questions" commonplaces. These commonplaces speak to the activities and tools (cognitive and physical) that scientists engage in and utilize in the process of scientific inquiry.

Formulation \#2, based on insights from laboratory studies and other sociological perspectives, underscores the notion that science is driven by interests, and that scientific knowledge is produced through social negotiation. The "context" and "goal or set of goals" commonplaces capture these aspects of science. For example, one could not think about the "context" of science without including the internal processes through which scientific knowledge is produced. Further, many ethnographic studies of the laboratory suggest that internal context is central to what scientific knowledge gets produced, and that, in some cases, the goal of the research is driven by personal, social, and/or political interests (Restivo, 1988).

Formulation \#3 broadens the scope of the commonplaces of science, emphasizing the connection between science and society. The flexibility of \#4 allows us to view "context" in another way. The larger social contexts — which include social, political, economic, religious, and ethical structures-influence and are influenced by all of the commonplaces of formulation \#4. That is, the practice of science can no longer be interpreted divorced from its larger context. Such issues 
as the contentious nature of allocating public money toward research, the tensions between conservationists and the business sector, the controversies around the meaning, value, and ownership of "intellectual property," the troubling connection between science and the military, and the heated debate over the ethics of cloning, involve more and more people from diverse interests, backgrounds, and with conflicting value systems in the day-to-day work of science. This is not to say that social forces are the sole determinants of the activity and products of science, but they play an increasingly significant role in it, and therefore must be considered when trying to under- stand the whole of science.

Commonplaces as Flexible. As noted, for a heuristic to be most useful, it also must be flexible. This formulation provides this flexibility and also attends to the multilayered nature of science. That is, as compared with the first three formulations, multiple meanings for each commonplace in \#4 exist.

For example, the term "lens" can refer to the particular perspective a scientist or group of scientists bring to a research problem or question. A lens influences a person's viewpoint; it determines what is considered important, what is considered unessential, and therefore what is worth paying attention to. It also can refer to the overall views science takes on the natural world. In this sense, the lens of science, we are told, is “objective” in its attempt to determine the nature of things. Most characterizations of the nature of science hold objectivity as the hallmark of science. However, when viewed in the light of the remaining commonplaces (e.g., context, goals, and the nature of scientific questions), the notion of an objective observer or process becomes problematic. In other words, discussions about the lens of science might raise issues around the various communities of scientists, bias, values, objectivity, and, ultimately, the questions that guide research.

For another example of the flexible nature of formulation \#4, as noted earlier, we use the term context to signify both the internal (or micro) and external (or macro) contexts of science (Cunningham, 1995). The micro context can refer to the space, time, resources, and conditions of the research; that is, where and when science happens. The laboratory is often invoked as the definitive internal context for scientific practice. Macro context can mean the sociocultural, economic, political, and historical milieu in which the science occurs. Some argue that the two cannot so easily be separated (Harding, 1986; Restivo, 1994). Context, then, can refer to the myriad situations that condition the work of scientists. These situations can result from the structure of practice in laboratories or the political, economic, and other social forces acting from both within and outside the laboratory walls.

What about "method"? In our view, method has to do with the specific processes a scientist or group of scientists follow to investigate a problem. It involves the employment of certain technologies and tools and procedures for their use. They also need to convince others that what they do and how they do it is going to produce valid and reliable results. 
There does not seem to be much consensus on a definition of scientific method, or a sense that such a thing even exists. Harding's (1986) point that different sciences employ different methods implies the salience of context; it matters what science one is talking about. Further, Millar (1994) suggests that method alone fails to provide us with an explanation of how science is different from other modes of inquiry. He argues that we should instead look at the constructs of science and their purposes, which points to the tight connection between the methods of science and the aims or goals methods are designed to serve. Here we see again how one commonplace cannot be decoupled from the rest.

Harding (1989) distinguishes between scientific method, "a technique for gathering evidence” (p. 21) and methodology, "the general theories, specific hypotheses, and other background assumptions that guide research" (p. 22). Given this distinction, Harding's methodology and our lens are essentially the same thing. Perhaps it makes sense to collapse the "lens" and "method" commonplaces into "methodology." This leaves us, however, without a commonplace to mark the very important technical aspects of doing science, and does not address the theory-laden nature of scientific method. ${ }^{1}$

Finally, the reader might be wondering at this point why we began each commonplace formulation with the terms "Science is an activity ...," after suggesting that there are many ways to view science. This assumption (i.e., that science is an activity) limits our formulations in perhaps important ways. However, we do not believe there is anything inherently wrong with this assumption. We simply wish to make explicit that the way we have formulated the commonplaces of science refers primarily to the activity of science. We follow Latour (1987) in starting with "the activity of making science and not the definition given by scientists or philosophers of what science consists of" (p. 174).

\section{IMPLICATIONS}

We have argued that considering science as a set of commonplaces offers a potentially powerful heuristic for thinking about science and science education. The power of the commonplaces heuristic lies in its demand for equal attention to multiple facets of science. Ignore one commonplace and the omission requires an explanation. The heuristic also provides the opportunity to meld perspectives from metascience disciplines and science education to connect theory and practice.

\section{Curricular and Pedagogical Implications}

Establishing the meanings of each commonplace can provide a useful basis for analysis of classroom practice, serve as a starting point to discuss the nature of science, and help teachers design instruction such that all aspects of the nature of science are included. Further, commonplaces can be established in such a way that renders them vulnerable to critique. In this way, lessons about science are highlighted; that is, the commonplaces themselves can become objects of study (and scrutiny). 
For example, with respect to \#3 and \#4, if the focus is on rethinking the nature of the scientific question to include issues of purpose, of intention, and the interests of students, then the instruction necessary to reflect this view might shift toward an open-ended, project-based, and student-centered orientation. If the context of science is reexamined, instruction might move beyond the natural sciences into other disciplines, such as history and sociology.

When students are asked to focus solely on traditional interpretations of method for doing science (i.e., are asked to march through the five steps) and are asked to memorize a collection of scientific facts and processes severed from a meaningful context, the goals of science reflected are straightforward. However, if the first five commonplaces in \#4 are construed more broadly, and more authentically, goals become multifaceted and complex.

\section{Implications for Teacher Educators}

One aspect of educating potential and practicing science teachers is enhancing their understanding of science, science teaching, and their role in the classroom. Using a commonplaces framework for thinking about science can do this. If teachers are asked to explore the definitions of each commonplace, and how each would translate in a classroom setting, then the links between the nature of science as described in the commonplaces and the teaching of science can be made explicit. Reciprocally, if teachers are given the opportunity to critically analyze science lessons using the commonplaces heuristic, the flexibility of both the definitions and the representations of the nature of science in and out of the classroom becomes apparent. This implies that science in the classroom can provide insights for understanding the nature of science.

Preservice teachers should experience the commonplaces of science from a variety of perspectives. For example, again related to \#4, prospective teachers should learn that the methods of science often do not conform to the textbook image they have encountered in the past. They should understand that there is no one scientific method, and different sciences typically employ different methods, tools, and techniques for their use (Bauer, 1992). Moreover, they should understand how the different sciences have different goals and ask different kinds of questions. Well-written cases from the history of science or the sociology of science, either gleaned from the literature or created by practicing teachers, could be useful for illustrating these points (e.g., Collins \& Pinch, 1993).

\section{Implications for Researchers}

As researchers of science classrooms and teachers' understandings of science and science education, we should always be looking for new and interesting ways to analyze and interpret our data. Using commonplaces as a basis for interpreting understandings about science and teaching practices provides opportunities for new frameworks through which to view teachers' or students' knowledge of the nature of science, science curriculum, or science instruction. Looking at classrooms or teachers' knowledge with the aid of this heuristic reminds us when certain 
aspects of science are overlooked, underplayed, or overemphasized. Or, the framework could be used to elicit teachers' knowledge about a set of commonplaces and where or whether they belong in school science instruction. Their understanding of how the commonplaces relate to one another would also be informative in terms of how they conceptualize the nature of science.

In addition to examining teachers' understandings of the nature of science the ways in which students engage in and interactionally define the commonplaces, one might utilize this heuristic to investigate teachers' representations of science in the classroom and curriculum. How do the ways in which the teacher structures the classroom environment allow for certain definitions, understandings, and participation in each of the commonplaces? What does this say about the teachers' understanding of the commonplaces?

\section{CONCLUSION}

Our goal in this study is not to argue for a more authentic science education; that is, make it more like real science. Instead, we present a heuristic — which emphasizes science as a contextualized activity - that provides a lens through which contexts of science learning can be critically examined. Our goal is to give direction to the study about science and science education such that aspects of the nature of science traditionally glossed over demand attention.

The difficulty with such a task is trying to be true to generations of research from science studies that emphasize different aspects of science's nature. While no definition of science can be representative of all perspectives, we argue that some formulations prove stronger than others in capturing much of the essence of scientific activity. Specifically, our fourth commonplaces formulation has the potential to emphasize the empirical, social, cultural, historical, economic, gendered, and political nature of science in ways that blend contributions from philosophers, sociologists, and historians of science.

\section{Note}

1 Thanks to an anonymous referee for alerting us to this point.

\section{REFERENCES}

American Association for the Advancement of Science (1989). Science for all Americans: A Project 2061 report on literacy goals in science, mathematics, and technology. Washington, DC: AAAS.

American Association for the Advancement of Science (1993). Benchmarks for scientific literacy. Washington, DC: AAAS.

Atwater, M. (1994). Research on cultural diversity in the classroom. In D. Gabel (Ed.), Handbook of research on science teaching and learning (pp. 558-576). New York: Macmillan. 
Barnes, B., \& Shapin, S. (Eds.) (1979). Natural order: Historical studies of scientific culture. Beverly Hills, CA: Sage.

Bauer, H. H. (1992). Scientific literacy and the myth of the scientific method. Chicago: University of Illinois Press.

Brickhouse, N. W. (1990). Teachers beliefs about the nature of science and their relationship to classroom practice. Journal of Teacher Education, 41, 53-62.

Bruner, J. (1960). The process of education. New York: Vintage.

California Department of Education (1990). Science framework for California public schools kindergarten through grade twelve. Sacramento, CA. CDE.

Callon, M. (1995). Four models for the dynamics of science. In S. Jasanoff, G. E. Markle, J. C.

Petersen, \& T. Pinch (Eds.), Handbook of science and technology studies (pp. 29-63). Thousand Oaks, CA: Sage.

Chalmers, A. (1982). What is this thing called science? Indianapolis, IN: Hackett.

Cobern, W. (1995). Science education as an exercise in foreign affairs. Science and Education, 4, 287-302.

Collins, H. M., \& Shapin, S. (1989). Experiment, science teaching, and the new history and sociology of science. In M. Shortland \& A. Warwick (Eds.), Teaching the history of science (pp. 67-79). Oxford, UK: Basil Blackwell.

Collins, H. M., \& Pinch, T. J. (1993). The Golem: What everyone should know about science. New York: Cambridge University Press.

Cozzens, S., \& Woodhouse, E. (1995). Science, government, and the politics of knowledge. In S. Jasanoff, G. E. Markle, J. C. Petersen, \& T. Pinch (Eds.), Handbook of science and technology studies (pp. 533-553). Thousand Oaks, CA: Sage.

Cunningham, C. M. (1995). The effect of teachers' sociological understanding of science on classroom practice and curriculum innovation. Unpublished doctoral dissertation, Cornell University.

Cunningham, C. M., \& Helms, J. (1998). Sociology of science as a means to a more authentic, inclusive science education. Journal of Research in Science Teaching, 35, 483-499.

Dickson, D. (1988). The new politics of science. Chicago: University of Chicago Press 
Duschl, R. (1990). Restructuring science education: The importance of theories and their development. New York: Teachers College Press.

Duschl, R. (1994). Research on the history and philosophy of science. In D. Gabel (Ed.), Handbook of research in science teaching (pp. 443-465). New York: Macmillan.

Duschl, R., \& Wright, E. (1989). A case study of high school teachers' decision making models for planning and teaching science. Journal of Research in Science Teaching, 26, 467-501.

Gallagher, J. J. (1991). Prospective and practicing secondary school science teachers’ knowledge and beliefs about the philosophy of science. Science Education, 75, 121-133.

Giere, R. N. (1988). Explaining science: A cognitive approach. Chicago: Chicago University Press.

Gieryn, T. (1995). Boundaries of science. In S. Jasanoff, G. E. Markle, J. C. Petersen, \& T. Pinch (Eds.), Handbook of science and technology studies (pp. 393-443). Thousand Oaks, CA: Sage.

Good, R. (1995). Comments on multicultural science education. Science Education, 79, 335336.

Haraway, D. (1990). Simians, cyborgs, and women: The reinvention of nature. New York: Routledge.

Harding, S. (1986). The science question in feminism. New York: Cornell University Press.

Harding, S. (1989). Is there a feminist method? In N. Tuana (Ed.), Feminism and science (pp. 17-32). Bloomington, IN: Indiana University Press.

Harding, S. (1990). Whose science? Whose knowledge? Thinking from women's lives. New York: Cornell University Press.

Keller, E. F. (1985). Reflections on gender and science. New Haven, CT: Yale University Press.

Kelly, G., Carlsen, W., \& Cunningham, C. (1993). Science education in sociocultural context: Perspectives from the sociology of science. Science Education, 77, 207-220.

Knorr-Cetina, K. (1995). Laboratory studies: The cultural approach to the study of science. In S. Jasanoff, G. E. Markle, J. C. Petersen, \& T. Pinch (Eds.), Handbook of science and technology studies (pp. 140-166). Thousand Oaks, CA: Sage.

Krugly-Smolska, E. (1996). Scientific culture, multiculturalism and the science classroom. Science and Education, 5, 21-29.

Kuhn, T. S. (1962). The structure of scientific revolutions. Chicago: University of Chicago Press. 
Latour, B. (1987). Science in action. Cambridge: Harvard University Press.

Latour, B., \& Woolgar, S. (1986). Laboratory life: The construction of scientific Facts.

Princeton, NJ: Princeton University Press.

Lederman, N. G. (1992). Students' and teachers' conception of the nature of science: A review of research. Journal of Research in Science Teaching, 29, 331-359.

Longino, H. (1990). Science as social knowledge: Values and objectivity in scientific inquiry. Princeton, NJ: Princeton University Press.

Loving, C. (1995). Comment on "multiculturalism, universalism, and science education." Science Education, 79, 341-348.

Matthews, M. (1991). History, philosophy, and science teaching. New York: Teachers College Press.

Matthews, M. (1994). Science teaching: The role of history and philosophy of Science. New York: Routledge.

Meichtry, Y. J. (1993). The impact of science curricula on student views about the nature of science. Journal of Research in Science Teaching, 30, 429-443.

Millar, R. (1994). What is 'scientific method' and can it be taught? In R. Levinson (Ed.), Teaching science (pp. 164-177). London: Routledge.

Millar, R. (1997). Science education for democracy: What can the school curriculum achieve? In R. Levinson \& J. Thomas (Eds.), Science today: Problem or crisis? (pp. 87-101). New York: Routledge.

National Research Council (1996). National science education standards. Washington, DC: National Academy Press.

Restivo, S. (1988). Modern science as a social problem. Social Problems, 35, 206-225.

Restivo, S. (1994). Science, society, and values: Toward a sociology of objectivity. Bethlehem, PA: Lehigh University Press.

Schwab, J. J. (1978). Science, curriculum, and liberal education. Chicago: University of Chicago Press.

Shapin, S. (1984). Pump and circumstance: Robert Boyle's literary technology. Social Studies of Science, 14, 481-520.

Solomon, J., \& Aikenhead, G. (Eds.)(1994). STS education: International perspectives on reform. New York: Teachers College Press. 
Solomon, J. (1994). Conflict between mainstream science and STS in science education. In J. Solomon \& G. Aikenhead (Eds.), STS education: International perspective on reform (pp. 3-10). New York: Teachers College Press.

Southerland, S. A. (1996). Acknowledging student agency: Multiculturalism, scientism, and science education. Paper presented at the annual meeting of the National Association for Research in Science Teaching, St. Louis, MO.

Stanley, W. B., \& Brickhouse, N. W. (1994). Multiculturalism, universalism, and science education. Science Education, 78, 387-398.

Traweek, S. (1988). Beamtimes and lifetimes: The world of high energy physicists. Cambridge, MA: Harvard University Press.

Yager, R. (Ed.)(1996) Science/technology/society as reform in science education. Albany, NY: SUNY Press.

Zeidler, D. L., \& Lederman, N. G. (1987). Science teachers' conception of the nature of science: Do they really influence teaching behavior? Science Education, 71, 721-734. 